\title{
Caracterização morfológica de adultos de Nusalala tessellata (Gerstaecker, 1888) (Neuroptera, Hemerobiidae)
}

\author{
Rogéria Inês Rosa Lara ${ }^{1}$ \\ Sérgio de Freitas $^{2}$
}

\begin{abstract}
Aвstract. Morphologic characterization of adult of Nusalala tessellata (Gerstaecker, 1888) (Neuroptera, Hemerobiidae). Adult of N. tessellata is redescribed based on morphological characters. 533 specimens were collected in São Paulo state in plantations of citrus (Santa Rosa de Viterbo), soybean (Nuporanga), cotton (Ribeirão Preto) and corn (Ribeirão Preto and Jaboticabal). Some other additional specimens collected on Sorghum bicolor (Lavras-MG) and Ilex paraguariensis (São Mateus do Sul, Cascavel-PR) were also studied. Illustrations obtained by SEM are given by first time.
\end{abstract}

KEYwORDs. Biological control; brown lacewing; hemerobiids; Neuropterida; predator.

\section{INTRODUÇÃO}

Os hemerobiídeos originaram-se no período Permiano e constituem um dos grupos mais primitivos da ordem Neuroptera (GoNZÁLEZ Olazo 1981). Sua ocorrência foi registrada para todos os continentes, à exceção da Antártida, e congregam cerca de 550 espécies agrupadas em 25 gêneros, 11 de ocorrência na Região Neotropical (OswaLd 1993).

A despeito do fato de que várias espécies de hemerobiídeos apresentam importância econômica como agentes de controle biológico (Agullar \& Lamas 1980; Chagas et al. 1982; Hussein 1984), os dados a respeito da taxonomia e biologia destes insetos são escassos, principalmente daqueles de ocorrência neotropical (MONSERRAT 1990a).

O gênero Nusalala Navás, 1913, de distribuição neotropical, pertence à subfamília Microminae e inclui vinte e duas espécies conhecidas (MonserRat 2000). As espécies deste gênero apresentam variações morfológicas o que favoreceu a ocorrência de muitas sinonímias (GonzÁlez Olazo 1993). Segundo Monserrat (1990b) as espécies deste gênero distribuem-se da Argentina ao México, assim como em Cuba, Haiti e Jamaica. No Brasil, ocorrem quatro espécies: $N$. falcata Kimmins, 1940, N. impudica (Gerstaecker, 1888), N. neotropica, (Esben-Petersen, 1914) e N. reticulata (Navás, 1910) (Monserrat 1990b).
As espécies de Nusalala apresentam asas anteriores com o Setor Radial tetra-ramificado, área costal estreita, três séries gradiformes e veias Média e Cúbito anterior fundidas (NAVÁs 1913). Kimmins (1936), examinando a espécie-tipo deste gênero, $N$. erecta Navás, 1913, observou a presença de uma veia umeral recorrente na área costal da asa anterior. Somando a isso caracteres morfológicos da genitália feminina, estabeleceu a sinonímia do gênero Haarupiella Esben-Petersen, 1914 com Nusalala.

GERSTAECKER (1888) descreveu Micromus tessellatus a partir de exemplares coletados em Santa Catarina, baseando-se na coloração geral do corpo e em caracteres da venação das asas (GonzÁlez Olazo 1993). NAVÁs (1910, 1923 e 1925) descreveu Micromus reticulatus, Haarupiella uruguaya e $H$. gradata. Penny \& MonserRat (1983) transferiram Micromus reticulatus para o gênero Nusalala; a mesma coisa, González Olazo (1987) com M. tessellatus Gerstaecker, 1888. GonzÁlez Olazo (1993) estabeleceu as sinonímias: $N$. reticulata (Navás, 1910), $N$. uruguaya (Navás, 1923) e H. gradata Navás, 1925 com $N$. tessellata (Gerstaecker, 1888).

Souza (1999) descreveu e ilustrou caracteres da venação das asas e da genitália externa de ambos os sexos de $N$. uruguaya $($ Navás, 1923) $=($ N. tessellata; GonzÁLEz Olazo, 1993 $)$ coletada em Lavras (MG).

Tendo em vista que os hemerobiídeos são considerados

1. Laboratório de Sanidade Animal e Vegetal, Instituto Biológico. Rua Peru 1472-A, 14075-310 Ribeirão Preto-SP, Brasil. Endereço eletrônico: rirlara@biologico.br

2. Departamento de Fitossanidade, Faculdade de Ciências Agrarias e Veterinárias, Universidade Estadual Paulista. Via de Acesso Prof. Paulo Donato Castellane s/n, 14884-900 Jaboticabal- SP, Brasil. Endereço eletrônico: serfre@ffcav.unesp.br 
eficientes agentes de controle biológico, que $N$. tesselata ocorre em vários agroecossistemas, e que para a sua identificação correta são necessários parâmetros morfológicos bem definidos, procurou-se com o presente trabalho caracterizar a morfologia externa de adultos, fornecendo assim subsídios para seu reconhecimento.

\section{MATERIAL E MÉTODOS}

Foram coletados 533 exemplares de $N$. tessellata em pomares de citros (Santa Rosa de Viterbo) e em plantios de soja (Nuporanga), algodão (Ribeirão Preto) e milho (Ribeirão Preto e Jaboticabal), no Estado de São Paulo.

Cada ponto de coleta, nos cultivos de soja, milho e algodão, foi composto por duas armadilhas de Moericke, dispostas a 0,5 e 1,0 m do nível do solo, fixadas em estacas de madeira com auxílio de aros de arame conforme proposto por PERIOTO et al. (2000). Utilizaram-se pratos plásticos de coloração amarela, com diâmetro de $15 \mathrm{~cm}$ e $4,5 \mathrm{~cm}$ de altura, industrializados pela Copobrás, referência PRF-Y. Próximo à borda dos pratos foram feitos dois furos com $1 \mathrm{~cm}$ de diâmetro recobertos por tecido de "voil", com a finalidade de escoar a água em caso de chuvas. Como conservante, foi usada solução aquosa de formalina e detergente a $1 \%$. As armadilhas foram mantidas no campo por três dias, sendo instaladas e retiradas durante o período da manhã. Para triagem dos insetos, o conteúdo das armadilhas foi vertido em peneiras plásticas recobertas com tecido de "voil" e, posteriormente, transferidos para frascos plásticos contendo álcool 70\%.

As armadilhas suspensas, utilizadas em plantio de citros, foram adaptadas daquela descrita por RAFAEL \& GORAYEB (1982), com uma redução, em $40 \%$ de suas dimensões.

Além dos exemplares obtidos por meio de coletas, foram também estudados exemplares provenientes de Lavras (MG), coletados em sorgo (Sorghum bicolor); de Cascavel e São Mateus do Sul (PR) coletados em cultura de erva-mate (Ilex paraguariensis); na área urbana de Ribeirão Preto (SP) e no Campus da Faculdade de Ciências Agrárias e Veterinárias, da Universidade Estadual Paulista, Jaboticabal (SP).

Para a mensuração dos caracteres utilizou-se microscópio estereoscópico equipado com ocular micrométrica de $1 \mathrm{~cm} /$ 100 divisões.

Mensurações. Cabeça, em vista frontal (Figs. 1, 3): largura da cabeça (lc): maior distância entre as margens externas dos olhos; largura dos olhos (lo): maior distância entre as margens interna e externa; altura dos olhos (ao): distância entre as margens inferior e superior do olho; largura do escapo (le): maior distância entre as margens laterais, tomada perpendicularmente ao eixo do comprimento do segmento; comprimento do escapo (ce): distância entre as margens basal e apical. Tórax, em vista dorsal (Fig. 7): comprimento do protórax (cp): maior distância entre as margens anterior e posterior do pronoto; largura do protórax (lp): maior distância entre as margens laterais do pronoto; comprimento da procoxa (cpc): distância entre as margens basal e apical; comprimento do fêmur (cf): distância entre as margens basal e apical; comprimento da tíbia (ct): distância entre as margens basal e apical; comprimento da asa (ca): distância entre a base e seu ponto apical; largura da asa (la): maior distância entre as margens anterior e posterior; largura da área costal (ac): maior distância entre as veias costa e subcosta.

As genitálias foram preparadas para dissecação por meio de maceração a quente em solução de hidróxido de potássio $(\mathrm{KOH})$ a $10 \%$, por 10 minutos, neutralizadas em ácido acético a $10 \%$, enxaguadas em água destilada e, quando necessário, coradas com Clorazol Negro a 1\%. Cada genitália foi montada, temporariamente, em lâmina escavada contendo glicerina para exame das estruturas e, posteriormente, mantidas em microtubos inclusas em glicerina, que foram fixados junto aos exemplares dissecados. Para a observação das genitálias utilizou-se um microscópio óptico e as ilustrações foram feitas com o auxílio de câmara-clara.

O material fotografado em microscópio eletrônico de varredura foi desidratado em bateria de álcool etílico de $80 \mathrm{a}$ $100 \%$, com incrementos de $5 \%$ e mantidos por 20 minutos em cada uma das soluções. As amostras passaram por secador de ponto crítico, foram recobertas por camada de $35 \mathrm{~nm}$ de ouro em metalizador e observadas e fotografadas em microscópio eletrônico de varredura JEOL - JSM 5410, operado a $15 \mathrm{kV}$.

Foi utilizada a nomenclatura de CARPENTER (1940) para a venação das asas.

Para a descrição das genitálias adotou-se a terminologia de EADY (1967) e TJEDER $(1954,1961,1970)$ que nomeou as partes de acordo com a estrutura e não quanto à origem. Assim, entoprocessus são processos laterais do gonarcus; o arcessus é uma estrutura móvel, fixada abaixo da parte mais alta do gonarcus, de forma bastante variável, presente em alguns gêneros de Neuroptera; o mediuncus é um processo ímpar direcionado posteriormente, em forma de gancho, que se origina na região posteromediana do gonarcus. Neste artigo, denominou-se arcessus a estrutura anteriormente chamada de mediuncus por MONSERRAT (2000) e endoprocessus medial e interno por Penny \& MonserRat (1983) e GonZÁlez Olazo (1993).

Os exemplares coletados foram preservados em álcool a $70 \%$ em frascos devidamente etiquetados e parte dos insetos foram montados em alfinetes entomológicos. O material estudado foi depositado nas coleções do Museu de Zoologia da Universidade de São Paulo, São Paulo (MZSP), do Instituto Biológico, São Paulo (IBSP) e do Departamento de Fitossanidade da Faculdade de Ciências Agrárias e Veterinárias da UNESP, Campus de Jaboticabal, Jaboticabal (FCAV).

Nusalala tessellata (Gerstaecker, 1888) (Figs. 1-20)

Micromus tessellatus Gerstaecker, 1888: 129

Micromus reticulatus Navás, 1910: 75; González Olazo, 1993: (syn.) Haarupiella uruguaya Navás, 1923: 193; González Olazo, 1993: (syn.) Haarupiella gradata Navás, 1925: 66; González Olazo, 1993: (syn.) Nusalala uruguaya; Kimmins, 1936: 576

Nusalala reticulata; Penny \& Monserrat, 1983: 901

Nusalala tessellata; González Olazo 1987: 43 

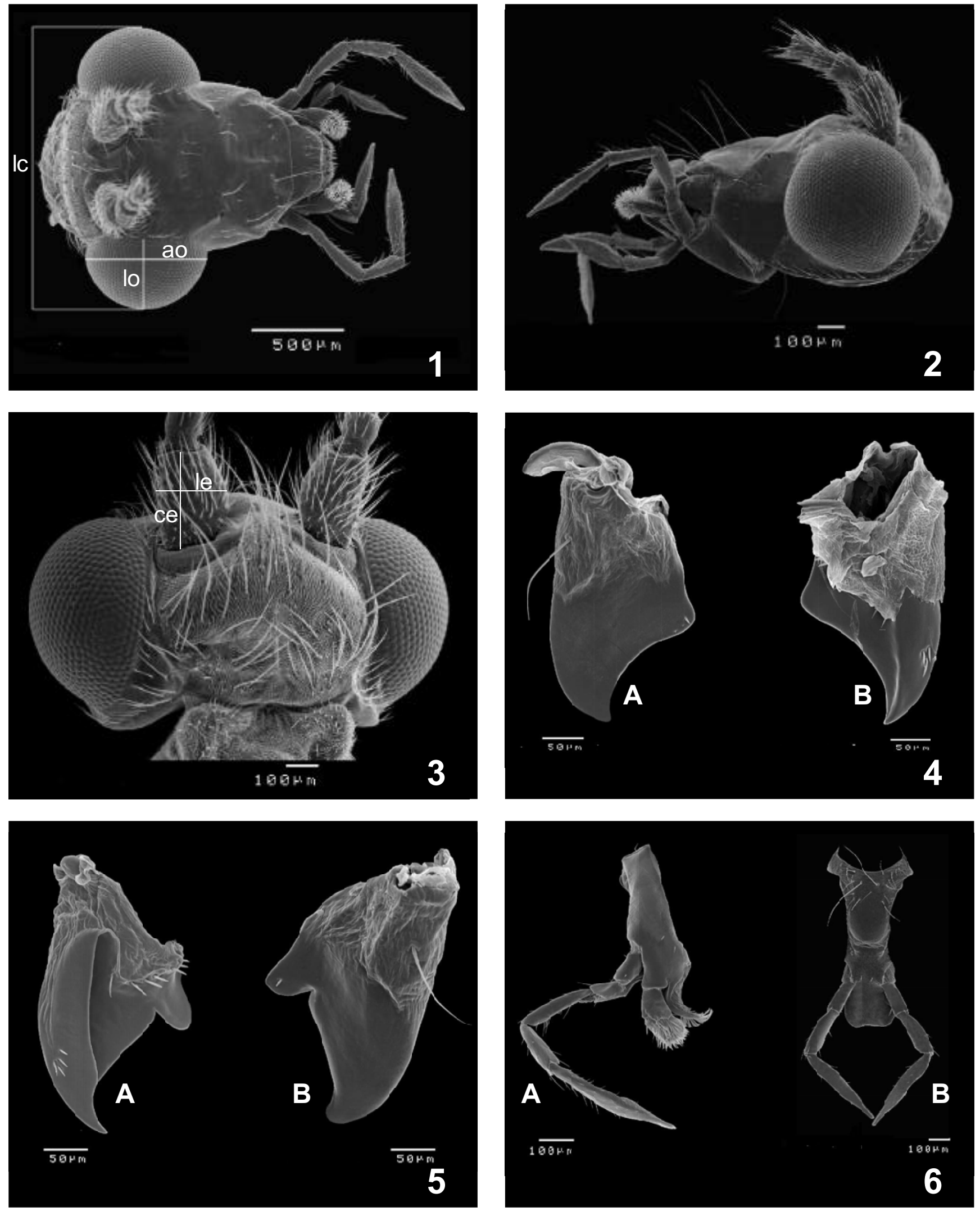

Figs. 1 - 6. Nusalala tessellata (Gerstaecker, 1888). 1, cabeça, vista frontral; 2, cabeça, vista lateral; 3, vértice, vista dorsal; 4, mandíbula direita, 4A, vista frontal, 4B, vista ventral; 5, mandíbula esquerda, 5A, vista ventral, 5B, vista frontal; 6A, palpo maxilar, vista dorsal; 6B, palpo labial, vista ventral; ao=altura do olho; ce=comprimento do escapo; lc=largura da cabeça; le=largura do escapo; lo=largura do olho. 
Coloração. Cabeça, região lateral e ventral do tórax, pernas e abdome predominantemente amarelo-palha; vértice com manchas marrons; escapo e pedicelo lateralmente sombreados de marrom; dorso torácico marrom-claro. Olhos escuros, com reflexos metálicos. Tíbias anteriores e medianas com duas manchas marrons nos terços basal e apical. Asas anteriores translúcidas, amarelo-palha, sombreadas de marrom-claro, mancha marrom na fusão de $\mathrm{MP} \mathrm{e} \mathrm{Cu1;} \mathrm{base} \mathrm{da} \mathrm{margem} \mathrm{anal} \mathrm{e}$ lóbulo jugal marrons; pterostigma indistinto. Asas posteriores translúcidas, amarelo-palha; pterostigma amarelado. Asas anteriores e posteriores com veias longitudinais marrons-claras intercalada por áreas de coloração amarelo-palha e séries gradiformes marrons, algumas das quais interrompidas medialmente.

Cabeça (Figs. 1,2). Bastante esclerotizada com largura 3,95,5 vezes a largura do olho (lc/lo), marcada pelas suturas transtorular, mesofrontal, transfrontal, sub-ocular, frontogenal e clípeogenal (sensu OswaLd 1993). Vértice elevado, coberto por microtríquias anteriormente, duas linhas de cerdas longas em forma de $\mathrm{V}$, um conjunto de cerdas na região médio-posterior direcionadas para o centro; algumas cerdas situadas lateralmente ao conjunto de cerdas mediano (Fig. 3). Olhos proeminentes, hemisféricos, 1,7-2,3 vezes mais altos que largos (ao/lo). Ocelos ausentes. Antenas moniliformes com número de antenômeros variando entre 60 e 63; escapo achatado 1,21,3 vezes mais longo do que largo (ce/le); flagelo com cerdas abundantes, curtas. Orifício tentorial anterior, na intersecção das suturas frontogenal e clípeogenal, bem demarcado. Labro com margens laterais oblíquas. Genas sem marcas, com cerdas esparsas; margem distal da fronte com um par de longas cerdas; margem distal do clípeo com dois pares de longas cerdas (Fig. 1). Mandíbulas assimétricas (Figs. 4, 5); a direita com projeção na margem interna, na superfície dorsal uma cerda longa láterobasalmente (Fig. 4A) e, na superfície ventral, três pequenas e grossas cerdas apicais (Figura 4B); a esquerda com dente pronunciado na margem interna, na superfície dorsal uma longa cerda na parte látero-basal (Fig. 5B) e, na superfície ventral, um sulco paralelo à margem externa, quatro pequenas e grossas cerdas apicais, sete pequenas e grossas cerdas basais (Fig. 5A). Palpo maxilar com cinco segmentos, palpômero basal dividido longitudinalmente (Fig. 6A), os demais simples, com cerdas longas esparsas, exceto na margem interna do $5 \mathrm{o}$, que apresenta um conjunto de diminutas cerdas; gálea bisegmentada, segmento distal com pilosidade densa e curta; região apical da lacínia densamente pilosa. Palpo labial com três segmentos, palpômeros simples, com cerdas longas e esparsas (Figura 6B), exceto na margem interna do 3o, que apresenta grande número de cerdas curtas na região apical; mento e submento achatados, com cerdas longas e esparsas; glossas e paraglossas fundidas, formando a lígula.

Tórax. Arqueado em vista lateral, coberto por microtríquias; pronoto e mesonoto com densa setose; setas esparsas na pleura (Fig. 7A). Protórax: pronoto 1,3-1,9 vezes mais largo que longo $(\mathrm{lp} / \mathrm{cp})$, com margens laterais arredondadas que cobrem parte dos escleritos laterais. Mesotórax: mesoscuto deprimido na região mediana com um par de áreas reniformes cobertas por cerdas mais curtas que o restante do tórax, localizadas lateralmente à depressão (Fig. 7B). Metatórax: metascuto grande e transverso. Pernas: ambulatórias com pilosidade densa e curta; procoxa alongada, cilíndrica, $0,7-0,8$ vezes o comprimento do fêmur (cpc/cf); meso- e metacoxa curtas e cônicas; comprimento dos fêmures e tíbias semelhantes, à exceção da metatíbia que apresenta comprimento $0,6-0,7$ vezes o do metafêmur (ct/cf); tíbia anterior com um esporão apical (Fig. 8A); tíbias mediana e posterior com dois esporões (Figs. 8B, 8C); tarsos pentâmeros, pré-tarso com um par de garras laterais e um empódio mediano, em forma de almofada. Asas: anteriores e posteriores com macrotríquias sobre as veias longitudinais, transversais da área costal e nas margens; membrana densamente coberta por microtríquias. Asa anterior (Fig. 9): 2,3 - 2,9 vezes mais longa que larga (caa/laa); área costal reduzida, $0,1-0,2$ vezes a largura máxima da asa (ac/laa); veia umeral recorrente pouco definida; veias transversais costais bifurcadas na metade proximal e simples na apical; uma veia transversal sc-r preestigmal; Rs e $\mathrm{R}$ em tronco único $(\mathrm{Rs}+\mathrm{R})$ com quatro ramos; três séries gradiformes (4 internas, 2 medianas e 7 externas), com algumas delas interrompidas medialmente; MA unida basalmente à radial; $\mathrm{MP}$ unida $\mathrm{a} \mathrm{Cu} 1$ por uma veia oblíqua, curta; duas veias transversais m-cu1 localizadas apicalmente à esta fusão; Cu1 proximal simples; 3 veias Anais, ramificadas; lóbulo jugal distinto. Asa posterior (Fig. 10): 0,8-0,9 vezes o comprimento da anterior (cap/caa), $2,4-3,0$ vezes mais longa que larga (cap/lap); área costal reduzida com veias transversais simples; subcostal espessa; Rs e R não coalescidas, tocando-se por meio de uma veia transversal; 2 séries gradiformes (3 internas e 6 externas), algumas interrompidas medialmente; MA unida à radial por uma transversal oblíqua.

Abdome. Subcilíndrico, com 10 segmentos; espiráculos presentes nos segmentos de 1 a 8 ; extremidade apical coberta de cerdas; nono e décimo tergitos bipartido, callus cercus com 16 - 19 trichobotrias (Fig. 11). Genitália masculina: nono tergito estendido anteroventralmente, sem projeções; nono esternito estendido posteroventralmente, arredondado apicalmente; ectoprocto subtriangular, com projeção posteroventral pequena e cônica (Fig. 19). Gonarcus: placas laterais amplas, arqueadas, com um par de projeções laterais longas e finas, os entoprocessus, maiores que a metade do comprimento do mediuncus (Fig. 12A), curvados ventralmente em vista lateral (Fig. 13) e divergentes em vista dorsal; arcessus de superfície coriácea (Fig. 12B), com células fechadas de tamanho e contorno irregulares (sensu EADY 1967), em vista dorsal lobos laterais arredondados posteriormente; ventralmente (Fig. 14) ligados por membranas a uma placa trapezoidal, da qual emerge posteriormente o mediuncus, o qual é longo, com extremidade apical aguda, em forma de gancho, curvado ventralmente. Parâmeros (Figs. 15, 16): situados abaixo do complexo gonarcus e acima do $9^{\circ}$ esternito; apófise proximal subcilíndrica, arqueada dorsalmente em vista lateral, longa, com extremidade apical arredondada; apófise lateral, posteriormente, com um par de lobos achatados dorsalmente e separados na região mediana por um espaço convergente, em forma de "U" (Fig. 

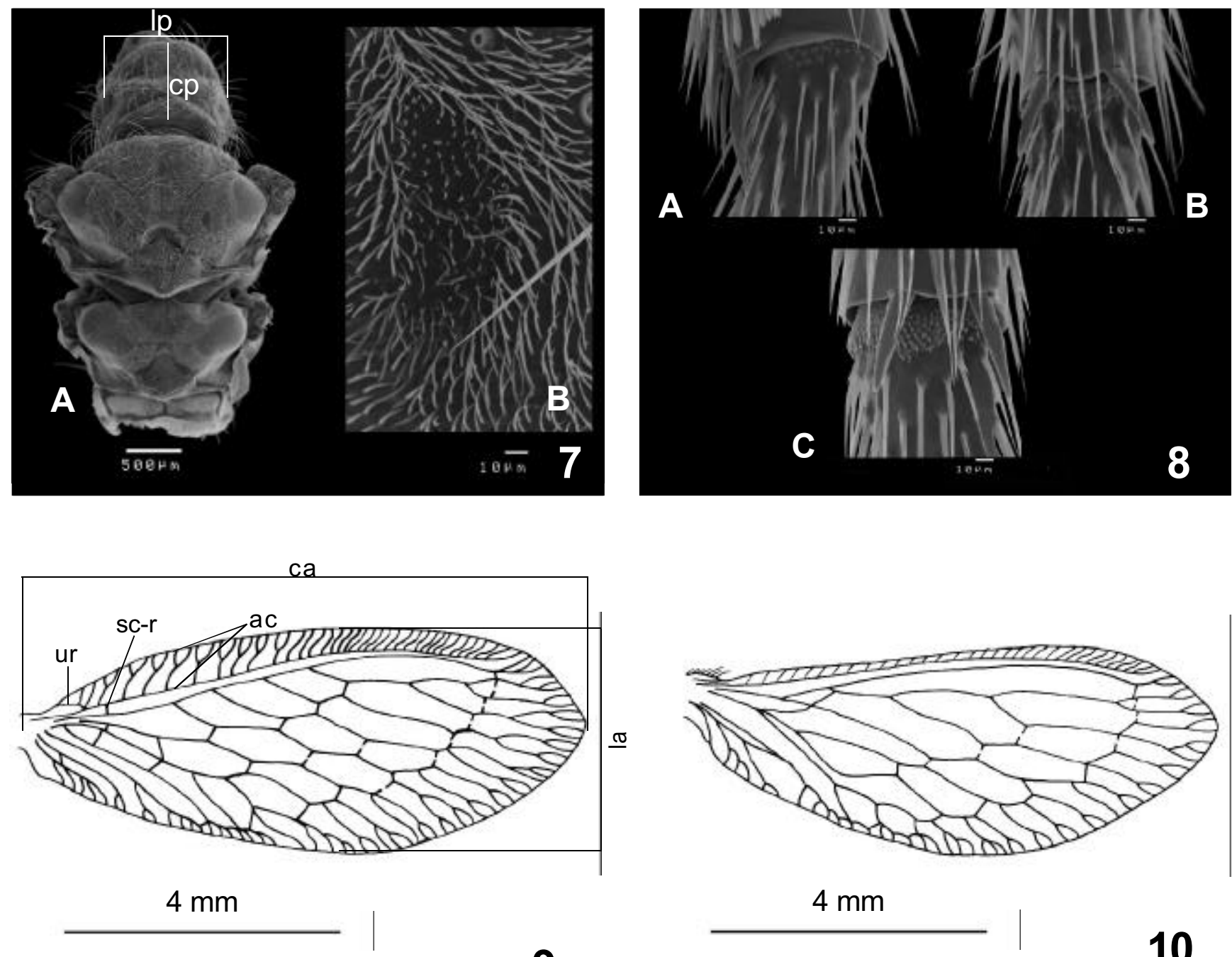

9
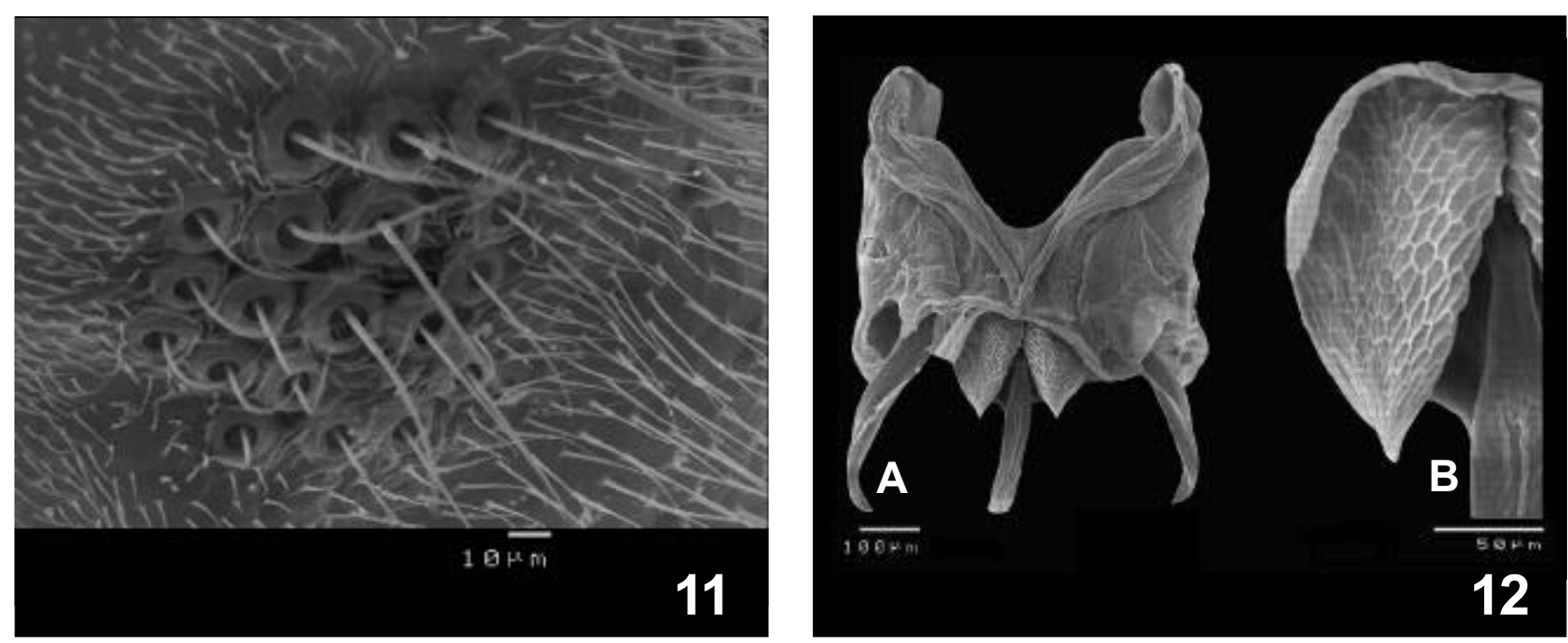

Figs. 7 - 12. Nusalala tessellata (Gerstaecker, 1888). 7A, tórax, vista dorsal; 7B, detalhe do mesoscuto; 8A, esporão tibial da perna anterior; 8B, esporões tibiais da perna mediana; $\mathbf{8 C}$, esporões tibiais da perna posterior; 9, asa anterior; 10, asa posterior; 11, trichobotria; 12A, gonarcus, vista dorsal; 12B, esculturações do arcessus; $\mathrm{ac}=$ largura da área costal; $\mathrm{ca}=$ comprimento da asa; $\mathrm{cp}=$ comprimento do protórax; la $=1$ largura da asa; lp=largura do protórax; sc-r=veia transversal; sc-r=preestigmal; ur=veia umeral recorrente. 


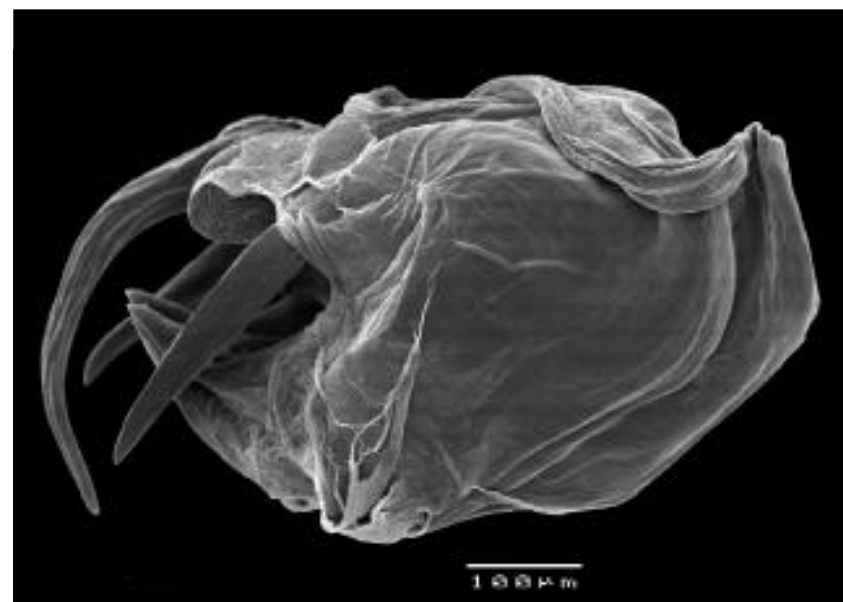

13
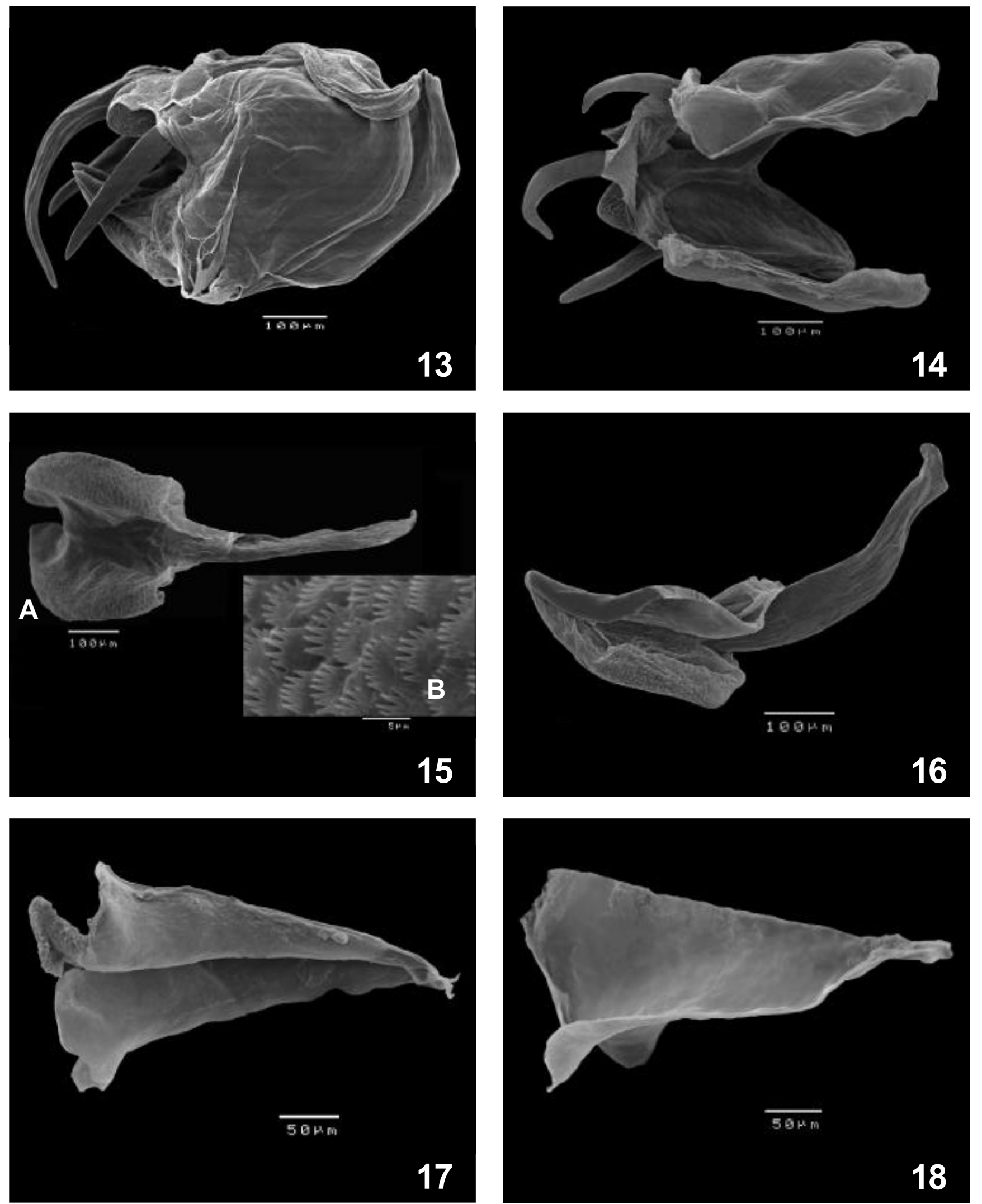

Figs. 13 - 18. 13, gonarcus, vista lateral; 14, gonarcus, vista ventral; 15A, parâmetros, vista ventral; 15B, gonocristae; 16, parâmetros, vista lateral. Nusalala tessellata (Gerstaecker, 1888). 17, hypandrium internum, vista ventrolateral; 18, hypandrium internum, vista dorsal. 

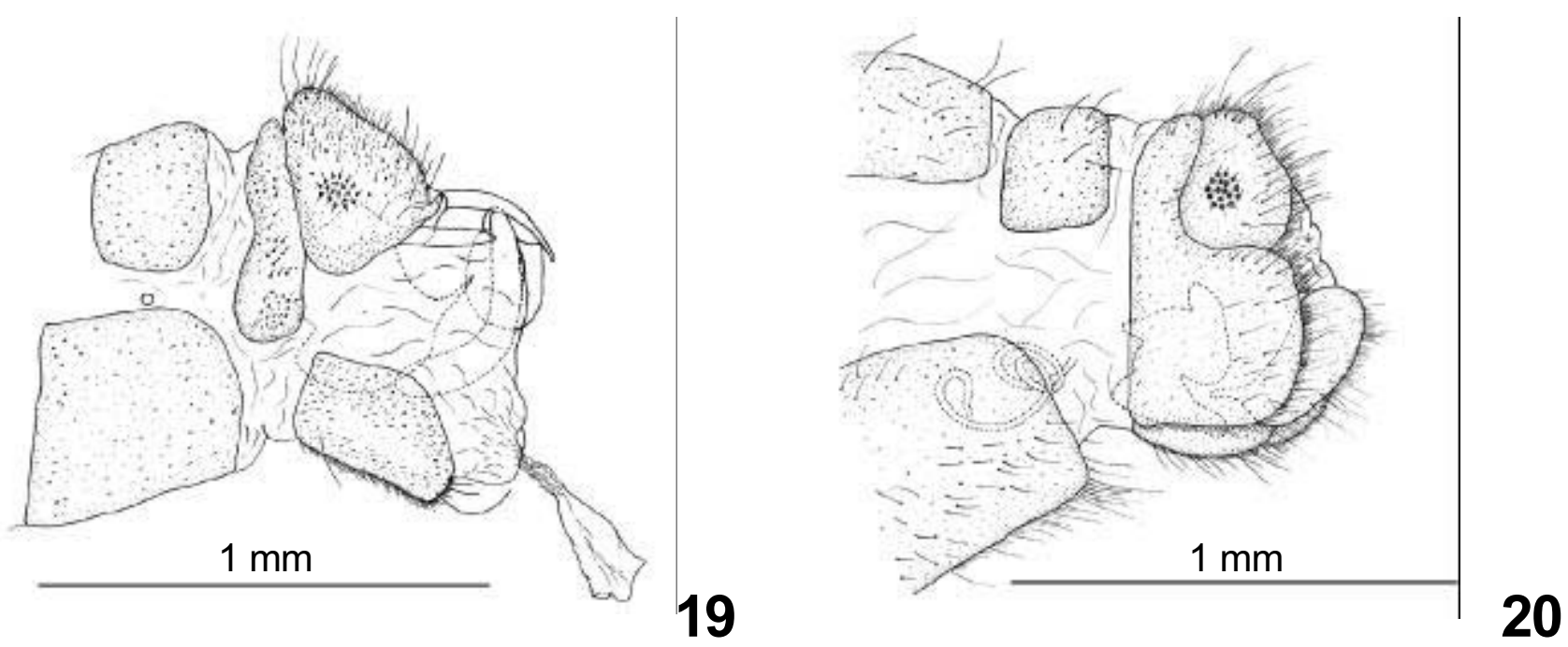

Figs. 19-20. Nusalala tessellata (Gerstaecker, 1888). 19, ápice abdominal do macho; 20, ápice abdominal da fêmea.

15A); superfície ventral dos lobos com gonocristae (Fig. 15B); porção posteromediana do parâmero coberta por membrana esclerotizada glabra e margem sinuosa (Fig. 16). Hypandrium internum triangular, deprimido medianamente; margem lateral anterior retorcida (Figs. 17, 18). Genitália feminina: oitavo tergito estendido ventralmente abrigando os espiráculos do $8^{\circ}$ segmento; oitavo esternito (também referidos como placa subgenital ou subgenitália) de contorno irregular; espermateca espiralada, de diâmetro uniforme em toda a sua extensão; nono tergito estendido posteroventralmente; nono esternito (gonapófises laterais) ovóide, com um processo posterodorsal digitiforme; ectoprocto sem projeção posteroventral; décimo esternito ausente (Fig. 20).

Material examinado. BRASIL. Minas Gerais: Lavras (Sorghum bicolor), 2 machos, 3 fêmeas, 12.XI.2000, R.S. Cavalcanti (MZSP, IBSP, FCAV). São Paulo: Jaboticabal (Zea mays), 3 machos, 18.I.2001, 2 machos, 1 fêmea, 16.II.2001, R.I.R. Lara (MZSP, IBSP, FCAV) (Macadamia integrifolia), 2 machos, 19.VII.2001, L. Hermanson, (MZSP, IBSP); Nuporanga (Glycine max), 2 machos, 2 fêmeas, 9.III.2000, 1 fêmea, 13.III.2000, 1 macho, 20.III.2000, 1 fêmea, 24.III.2000, 2 machos, 27.III.2000, R.I.R. Lara (MZSP, IBSP, FCAV); Ribeirão Preto, 1 macho, 1 fềmea, 29.I. 2001, Ribeirão Preto, 21¹1'11''S; 4751'44"O (Gossypium hirsutum), 2 machos, 19.II.2001, 2 machos, 24.II. 2001, 1 macho, 1 fêmea, 21. III.2001 (Zea mays), 1 macho, 16.III.2001, 2 machos, 1 fêmea, 9.IV.2001, 2 machos, 1 fêmea, 12.IV.2001, R.I.R. Lara (MZSP, IBSP, FCAV); Santa Rosa de Viterbo (Citrus), 1 macho, 17.II.2001, 2 machos, 12.III.2001, 1 macho, 1 fêmea, 21.III.2001, 1 fêmea, 24.III.2001, R.I.R. Lara (MZSP, IBSP, FCAV). Paraná: Cascavel (Ilex paraguariensis), 2 machos, 30.VI.1999; São Mateus do Sul (Ilex paraguariensis), 1 macho, 1 fêmea, 17.XI.1999, M.S.P. Leite,. (MZSP, IBSP, FCAV).

\section{DISCUSSÃO}

Nos espécimes estudados o número de antenômeros variou entre 60 e 63. PenNy \& MonserRat (1983) encontraram números semelhantes, que variaram de 61 a 62 em espécimes provenientes da Bacia Amazônica.

Em todos os exemplares estudados observou-se a presença de apenas um esporão nas tíbias anteriores, o que se contrapõe às observações de SouzA (1999), que cita a presença de dois esporões em todas as tíbias. O comprimento das asas anteriores variou de 7,7 a $8,9 \mathrm{~mm}(\mathrm{n}=10)$ para os machos e de 6,8 a $8,9 \mathrm{~mm}$ $(\mathrm{n}=10)$ para as fêmeas. PenNy \& MonserRat (1983) encontraram 8,1 a 9,0 mm (machos) e 8,0 a 9,6 mm (fêmeas), enquanto que GonzÁlez Olazo (1993), não fazendo distinção de sexo, apresentou dados que variaram de 7,5 a 9,8 $\mathrm{mm}$.

Observou-se variação no Setor Radial das asas anteriores: $12,2 \%$ dos espécimes apresentaram variação na série gradiforme externa, $14,1 \%$ na mediana e $7,7 \%$ na interna. Em $67,5 \%$ destes exemplares observou-se que a variação morfológica foi unilateral. Alguns espécimes apresentaram apenas uma veia m-cul antes da fusão da MP com Cu1.

PenNy \& MonserRat (1983) relataram que a área costal desta espécie é reduzida, menor que $1 / 6$ da largura máxima da asa, sem indicar, no entanto, o ponto onde foi realizada tal medida. Nos espécimes estudados encontrou-se $0,14-0,20$ vezes para a maior largura da área costal.

PenNy \& MonserRat (1983) referiram-se às placas laterais do gonarcus como não totalmente fundidas medialmente. No entanto, em todos os exemplares estudados estas peças apresentaram-se totalmente fundidas.

\section{REFERÊNCIAS}

Aguilar F., P. G. \& J. M. Lamas. 1980. El cultivo del algodonero. Revista Peruana de Entomologia 23(1): 91-97.

Carpenter, F. M. 1940. A revision of the Neartic Hemerobiidae, Berothidae, Sisyridae, Polystoechotidae and Dilaridae (Neuroptera). Proceedings of the American Academy of Arts and Sciences 74(7): 193280 . 
Chagas, E. F.; S. Silveira Neto; A. J. B. P. Braz; C. P. B. Mateus \& I. P. Coelho. 1982. Flutuação populacional de pragas e predadores em citros. Pesquisa Agropecuária Brasileira 17(6): 817-824.

EADY, R. D. 1967. Some illustrations of microsculpture in the Hymenoptera. Proceedings of the Royal Entomological Society of London 43(4-6): 66-72.

GonzÁlez Olazo, E. V. 1981. El genero Megalomus Rambur (Neurop.Planipennia-Hemerobiidae) en Argentina y Chile. Acta Zoológica Lilloana 36(2): 97-113.

González Olazo, E. V. 1987. Los neuropteros asociados com los cultivos citricos de la provincia de Tucuman y description de una nueva especie de Nomerobius (Hemerobiidae). Cirpon, Revista de Investigation 5(1-4): 37-54.

González Olazo, E. V. 1993. Contribucion al conocimiento de las especies de Nusalala (Neuroptera, Planipennia, Hemerobiidae) de la Argentina. Acta Zoológica Lilloana 42(2): 215-224.

Hussein, M. Y. 1984. A spray technique for mass release of eggs of Micromus tasmaniae Walker (Neuroptera: Hemerobiidae). Crop Protection 3(3): 369-378.

Kimmins, D. E. 1936. New species of Nusalala (Neuroptera, Hemerobiidae). Annals and Magazine of Natural History 17(101): 568-576.

Monserrat, V. J. 1990a. Systematic studies on Hemerobiidae, p. 67-88. In: M. W. Mansell \& H. AspöcK (ed.) Advances in Neuropterology. Proceedings of the Third International Symposium on Neuropterology. Pretoria, $298 \mathrm{p}$.

Monserrat, V. J. 1990b. A systematic checklist of the Hemerobiidae of the world (Insecta: Neuroptera), 215-262. In: M. W. Mansell \& H. Aspöck (ed.) Advances in Neuropterology. Proceedings of the Third International Symposium on Neuropterology. Pretoria, $298 \mathrm{p}$.

Monserrat, V. J. 2000. Revisión del género Nusalala (Neuroptera, Hemerobiidae). Fragmenta Entomologica 32(1): 83-162.

NAVÁs, L. 1910. Hemeróbidos (Ins. Neur.) nuevos, com la clave de las tribus y géneros de la familia. Broteria 9: 69-90.

NAvÁs, L. 1913. Névroptères. In: Mission du service géographique de l'armée pour la mesure dún arc de Méridien équatorial en Amérique du sud sous le contrôle scientifique de l'Académie des Sciences 1899-1906 10(1): 69-77.

NAVÁs, L. 1923. Estudis sobre neurópters (Insectes). Arxius de L'Institut de Ciéncies 7: 179-203.

NavÁs, L. 1925. Neuropteren aus Brasilien. Mitteilungen der Münchener Entomologischen Gesellschaft 15: 64-68.

OswaLD, J. D. 1993. Revision and cladistic analysis of the world genera of the family Hemerobiidae (Insecta: Neuroptera). Journal of the New York Entomological Society 101(2): 143-299.

Penny, N. D. \& V. J. Monserrat. 1983. Neuroptera of the Amazon basin Part 10-Hemerobiidae. Acta Amazonica 13(5-6): 879-909.

Perioto, N. W.; R. I. R. Lara; J. C. C. Santos \& T. Silva. 2000. Utilização de armadilhas de Moericke em ensaios de seletividade de inseticidas em himenópteros parasitóides. Arquivos do Instituto Biológico 67(supl.): 93.

Rafael, J. A. \& I. S. Gorayeb. 1982. Uma nova armadilha suspensa e primeiros registros de mutucas de copas de árvores. Acta Amazônica 12(1): 232-235.

SouzA, B. 1999. Aspectos morfológicos de adultos de Nusalala uruguaya (Navás, 1923) (Neuroptera: Hemerobiidae). Ciências e Agroteconologia 23(2): 252-257.

TJeDER, B. 1954. Genital structures and terminology in the order Neuroptera. Entomologiske. Meddelelser 27: 23-40.

TJEDER, B. 1961. Neuroptera - Planipennia. The lacewings of Southern Africa 4. Family Hemerobiidae, p. 296-408. In: B. Hanstrom; P Brinck \& G. Rudebec (eds.). South African Life. Stockholm, Swedish Natural Science Research Council.

TJeDER, B. 1970. Neuroptera, p. 89-99. In: S. L. Tuxen (ed.) Taxonomist's glossary of genitalia in insects. Copenhagen, Scandinavian University Books, 359p. 